\title{
EDUCACIÓN EMOCIONAL EN LA FORMACIÓN DEL DOCENTE DE LA SOCIEDAD RED
}

La sociedad actual nos sitúa ante una realidad en la que la adaptación a los procesos de cambio exige el desarrollo de nuevas competencias, alejadas de las que tradicionalmente eran necesarias para un desenvolvimiento exitoso. Dentro de este contexto la educación se erige como el principal motor que ha de propiciar un desarrollo social sostenible, lo que supone profundas transformaciones que dirijan sus esfuerzos hacia la adquisición de competencias que forjen las dimensiones inter e intrapersonales dentro de esta visión humanista de la educación.

Ante esta situación los organismos e instituciones nacionales e internacionales han promovido estudios y recomendaciones que tienen como objetivo la mejora de la competencia profesional del profesorado como paso inexcusable para el cambio y mejora de los sistemas educativos. Dentro de esta configuración competencial del desempeño docente partimos del Modelo Europeo identificando cinco ámbitos: saber, saber ser, saber hacer qué, saber hacer cómo y saber estar. Así, el desarrollo de la competencia emocional por parte de los docentes se hace del todo necesario para promover la adquisición de las capacidades en cada una de las áreas descritas, adquiriendo un carácter transversal y facilitador.

La formación del docente en aspectos relacionados con la educación emocional proporciona un campo de investigación y estudio en el que se determine su importancia en la configuración de las competencias docentes, así como su relación con el éxito educativo a través del incremento de la calidad de los sistemas, provenientes de la mejora de los resultados obtenidos por el alumnado.

Desde estas premisas surge el presente monográfico, que recoge doce artículos con las aportaciones de acreditados autores y grupos de investigación que reflexionan y estudian en torno a la Inteligencia Emocional.

Comienza el volumen con el artículo de Pinedo, Arroyo y Caballero titulado Afectividad positiva y negativa en el futuro docente: relaciones con su rendimiento académico, salud mental y satisfacción con la vida, que evalúa el nivel de afectividad positiva y negativa experimentada por este colectivo y explora las relaciones existentes entre éstas y los niveles de rendimiento académico, salud mental y satisfacción con la vida en los futuros maestros.

La segunda contribución recae sobre Hortigüela, Ausín, Abella y Delgado, que en su contribución Percepción de docentes y estudiantes sobre el trabajo de edu- 
cación emocional en el aula, contrastan la opinión de los estudiantes del Grado en Educación Primaria, de los profesores universitarios de la titulación y de los maestros en activo de esta etapa obligatoria acerca el rol que debe desempeñar la educación emocional en el aula.

Continúan Molero, Pantoja y Galiano con una propuesta denominada Inteligencia Emocional. Rasgo en la formación inicial del profesorado, en la que presentan un estudio que analiza la Inteligencia Emocional (IE) en el alumnado de los grados de Educación Infantil y Educación Primaria durante su formación inicial siguiendo el modelo IE rasgo, en concreto el modelo del bienestar de Bar-On.

Con el artículo titulado El desarrollo de la inteligencia emocional a través de la optimización de las capacidades cognitivas a través de la educación obligatoria, Mestre, Pérez, González y Nuñez aportan una propuesta teórica como base para el desarrollo de la Inteligencia Emocional en la educación obligatoria.

La quinta contribución corresponde a Buitrago, Ávila y Cárdenas, que en un trabajo denominado El sentido y el significado atribuido a las emociones por el profesorado en formación de la Universidad pedagógica y tecnológica de Colombia, muestran el sentido y el significado que los maestros en formación asignan a las emociones. Es el resultado de una investigación de tipo cualitativo que utiliza la metodología de estudio de caso y la técnica de entrevista a profundidad.

Bajo el titulo Análisis del autoconcepto y realización personal: nuevos desafíos en la formación inicial del profesorado, Pegalagar también se ocupa de la formación inicial del profesorado, analizando valores asociados al autoconcepto y a la realización personal en los estudiantes del Grado de Educación Infantil.

Al igual que las anteriores, es de enorme interés la contribución de Escolar, De la Torre, Huelmo y Palmero, que aborda la Educación emocional en los profesores de Educación Infantil como aspecto clave en el desempeño docente mediante un estudio de carácter descriptivo y transversal en el que se analiza la oferta formativa sobre educación emocional impartida desde los Centros de Formación e Innovación educativa, constatando que este tipo de acciones se ha triplicado en los últimos años, siendo los centros públicos lo que en su mayoría los realizan.

El siguiente artículo corresponde a García y Sánchez, quienes presentan El aprendizaje Servicio y el desarrollo de las competencias emocionales en la formación inicial del profesorado, con el objetivo de hacer visible y analizar la conciencia del desarrollo emocional del alumnado de Grado de Educación Infantil que participa en las experiencias de Aprendizaje y Servicio, que se realizan dentro de un itinerario que persigue la institucionalización curricular del mismo.

Otra propuesta que versa sobre el aprendizaje servicio es la que aporta Carrica, con el título La educación emocional del docente y su labor: una experiencia de aprendizaje-servicio en la universidad y su evaluación. Muestra una experiencia de Aprendizaje-Servicio (ApS) -y su evaluación- como una manera de colaboración, servicio y mejora de la comunidad. Para ello analiza el contexto teórico del ApS como metodología en relación con el desarrollo comunitario y la inteligencia emocional, y describe una experiencia de ApS Ilevada a cabo en los grados de educación.

Palomera, Briones y Gómez linares evidencian en su trabajo Diseño, desarrollo y resultados de un programa de educación socio-emocional para la formación de do- 
centes a nivel de grado y postgrado, la escasez de programas dirigidos a la educación emocional para los docentes y presentan dos propuestas pioneras dirigidas a la educación emocional, tanto en la formación inicial como permanente del profesorado

En la siguiente propuesta, los autores Bernal y Donososo abordan una investigación sobre el bienestar docente vinculado al fenómeno denominado engagement, justificándolo como una vía de solución para combatir el malestar docente y promover el bienestar. Para ello levan a cabo un estudio exploratorio de carácter cualitativo, utilizando el método biográfico-narrativo y la técnica de la entrevista, con la finalidad de avanzar en esta línea formativa.

Para finalizar el apartado de artículos, Peñalva, López y Barrientos realizan una revisión bibliográfica de la literatura especializada para establecer la relación que existe entre los conceptos de burnout, engagement, inteligencia emocional y habilidades emocionales, constatando que cada vez son más los trabajos que avalan la relación existente entre ellos, y que apuestan por la formación de los docentes en el ámbito específico de la inteligencia emocional como herramienta adecuada para la gestión positiva del burnout hacia el engagement.

Como cierre del monográfico Aurora Bernal realiza una breve reseña sobre la obra escrita por López Valero y Encabo, y publicada en 2016, que lleva por título Fundamentos didácticos de la lengua y la literatura.

Se trata en definitiva de una propuesta amplia en torno a ámbitos diversos que no hace más que evidenciar el reto pedagógico que supone la educación emocional y el necesario proceso de reflexión y análisis en la formación del docente de la Sociedad Red. 